\title{
Lymphatic sparing laparoscopic varicocelectomy with or without testicular artery preservation: is there a difference?
}

\author{
Abdelaziz Yehya ${ }^{1,2^{*}}$ D, Mohamed Abdalrazek ${ }^{1,2}$, Ibrahim Gamaan ${ }^{1,2}$, Ahmed Fathy $^{3}$ and Wael El Batal ${ }^{3}$
}

\begin{abstract}
Background: Lymphatic sparing laparoscopic Palomo varicocelectomy is a safe and reliable technique for varicocele treatment in adolescents and children. The purpose of this study was to compare the outcomes of lymphatic sparing laparoscopic varicocelectomy with and without testicular artery preservation. The prospective random allocation of selected patients was done at Al-Azhar University Hospital, Pediatric Surgery Department from February 2010 till January 2015. All patients underwent lymphatic sparing laparoscopic varicocelectomy and they were divided into two equal groups, group A underwent laparoscopic Palomo without testicular artery sparing and group B underwent the procedure with testicular artery sparing. The main outcome included operative time, postoperative hydrocele, and persistence of varicocele, together with catch-up testicular growth or testicular atrophy.

Results: One hundred and sixty male patients presented with left-sided primary varicocele that was diagnosed clinically and affirmed by color Doppler ultrasonography. The mean age was $14.25 \pm 1.6$ years (ranged 13-16 years). There was one case of persistent varicocele in group A, compared to 8 cases in group B with a statistically significant difference $(p=0.016)$. A significant difference had been found in the operative time $(p=0.001)$ between both groups. No hydrocele or testicular atrophy had been detected in both groups. No significant inter-group differences were seen in aspects of age, varicocele grade, and catch-up testicular growth. The mean follow-up period was 42 months (24-60 months).
\end{abstract}

Conclusion: Lymphatic sparing laparoscopic Palomo varicocelectomy was superior to that with testicular artery preservation as regard varicocele persistence and operative time and hence is preferable for the management of primary pediatric varicocele.

Keywords: Laparoscopic varicocelectomy, Lymphatic sparing, Testicular artery preservation

\section{Introduction}

One of the most common urologic abnormalities is varicocele. It is found in adolescent males ranging from $15-19$ years old with $15 \%$ incidence [1]. For diagnosing varicocele, clinical diagnosis, testicular volume measurement by ultrasound (U/S) and staging of the varicocele

\footnotetext{
* Correspondence: drabdelazizyehya@yahoo.com

${ }^{1}$ Department of Pediatric Surgery, Faculty of Medicine Al-Azhar University,

Nasr City, Cairo, Egypt

${ }^{2}$ Department of Pediatric Surgery, Al-Azhar University Hospitals, Darrasa,

Cairo, Egypt

Full list of author information is available at the end of the article
}

are the main steps [2]. Sperm count and fertility are highly related to testes. In the routine assessment of varicocele in adolescents, semen parameters are not included [3].

Patients with varicocele complaining of scrotal discomfort or pain may suffer from progressive damage of the testicular tissue, resulting in hypotrophy [4]. Varicocelectomy has numerous approaches as microsurgical subinguinal (Goldstein), inguinal (Ivanissevich), abdominal (Palomo), and laparoscopic and sclerotherapy (antegrade and retrograde) [5]. The incidence of hydrocele formation after varicocelectomy is variable and attributed to

\section{Springer Open}

(c) The Author(s). 2020 Open Access This article is licensed under a Creative Commons Attribution 4.0 International License, which permits use, sharing, adaptation, distribution and reproduction in any medium or format, as long as you give appropriate credit to the original author(s) and the source, provide a link to the Creative Commons licence, and indicate if changes were made. The images or other third party material in this article are included in the article's Creative Commons licence, unless indicated otherwise in a credit line to the material. If material is not included in the article's Creative Commons licence and your intended use is not permitted by statutory regulation or exceeds the permitted use, you will need to obtain permission directly from the copyright holder. To view a copy of this licence, visit http://creativecommons.org/licenses/by/4.0/. 
lymphatic obstruction. Lymphatic sparing varicocelectomy was associated with a decreased incidence of postoperative hydrocele. The hydrocele formation occurred significantly less frequently in the lymphatic sparing in comparison to the non-sparing surgery (1.9\% vs. $17.9 \%)$ [6].

The purpose of the study was to clarify the comparison between the outcomes of lymphatic sparing laparoscopic varicocelectomy with or without testicular artery preservation as regards the operative time, persistence of varicocele, development of post-operative hydrocele, and catch-up of testicular growth or testicular atrophy.

\section{Patients and methods}

The study was done at the pediatric surgery department, Al-Azhar University Hospitals, in Cairo, from February 2010 till January 2015, with ethical committee approval, and informed written consent from all patients. Patients were divided into two equal groups. Group A, underwent lymphatic sparing laparoscopic Palomo varicocelectomy (without testicular artery preservation) and group B underwent lymphatic sparing laparoscopic varicocelectomy with testicular artery preservation (only testicular vein clipping). Random selection was done in the operating room through sealed envelopes. The varicocele was graded from 1 to 3 grades according to the severity (Dubin and Amelar classification). Grade 1 vein dilatation palpable during Valsalva's maneuver, grade 2; palpable in an upright position without Valsalva's maneuver and grade 3; palpable and visible dilated veins through scrotal skin in the upright position without Valsavla's maneuver [7]. U/S scan with color Doppler was done for all patients to confirm the diagnosis, assess the size and determine the severity of venous reflux. The testicular volume for both testicles was measured by U/S using the formula $(0.71 \times$ length $\times$ width $\times$ height $)[8]$.

\section{Inclusion criteria}

Symptomatic patients with primary left-sided refluxing varicocele grade 1, 2, or 3 with testicular pain (discomfort or scrotal heaviness), or testicular asymmetry defined as $20 \%$ or greater volume differential between both testicles.

\section{Exclusion criteria}

Concomitant left-sided hernia or hydrocele or previous left-sided groin surgery, patients refused to participate in the study or lost to follow-up postoperatively.

\section{Surgical procedure}

After induction of general anesthesia, and while the patient was in slight Trendelenburg position, and from about 5 to $10 \mathrm{~min}$ before trocar insertion, intraparenchymal injection of $2 \mathrm{ml}$ of $1 \%$ methylene blue dye
(MB) in the left testicle was accomplished using a 21gage needle, followed by gentle massage of the scrotum for about $1 \mathrm{~min}$. All patients underwent laparoscopic varicocelectomy with modification in the form of sparing of the lymphatic vessels with (group B) and without (group A) testicular artery preservation. Open Hasson technique was used for insertion of the first trocar through a sub-umbilical incision about $5 \mathrm{~mm}$ in length. Pneumoperitoneum was established to a pressure of 12 $\mathrm{mmHg}$ followed by placement of two 5-mm working ports lateral to the umbilicus on both sides. In group A, and after identification of the testicular vessels, an incision was done in the peritoneum alongside the testicular vessels and as high as possible above the internal ring. Stained lymphatics were identified through its bluish contents that persist for about 35-45 min after injection. Stained lymphatics were isolated from the vascular pedicle and the remaining vessels were dissected free and divided after clipping. In group B, the testicular artery was identified, through its pulsations, and preserved. If the pulsations were not apparent, installation of 0.5 to 2 $\mathrm{ml}$ diluted papaverine $(30 \mathrm{mg}$ papaverine hydrochloride in $10 \mathrm{ml}$ saline) over the testicular vessels was done while decreasing $\mathrm{CO} 2$ pressure for about $1 \mathrm{~min}$. The testicular artery and the lymphatic vessels were meticulously identified and preserved. Testicular veins were isolated, clipped, and divided. Then, the Co2 was expelled and the abdomen was deflated, and the working ports were extracted under direct vision followed by the umbilical port. All the port sites were repaired by absorbable sutures. Postoperatively, the parents were informed about the expected change of the patient's urine color for about 24 to $48 \mathrm{~h}$ after surgery.

\section{Follow-up}

All patients were followed up at the outpatient clinic. Firstly, 1 week postoperatively for port sites wound check and then after $1,3,6,12,18$, and 24 months for assessment and calibration of the testicular volume (testicular catch-up growth or atrophy), persistence of varicocele or postoperative hydrocele formation. All findings were confirmed by color Doppler U/S every visit during the follow-up period. The testicular atrophy was defined as a decrease in the size of the testicle by more than $20 \%$ in relation to the contralateral testis. Testicular catch-up defined as a decrease in asymmetry to less than $20 \%$ that is confirmed by U/S. The testicular size was evaluated by U/S with every follow-up visit. All patients were treated by the same surgical team, the first three authors.

\section{Statistical methods}

Sample size calculation was done by MedCalc ${ }^{\circ}$ version 12.3.0.0 program, statistical calculator based on $95 \%$ 
confidence interval, and power of the study $80 \%$ with $\alpha$ error $5 \%$. These values were calculated using sample size producing a minimal sample size for each group 80 cases.

\section{Statistical analysis}

The Statistical Package for Social Sciences program (SPSS) version 20 software tabulated and statistically analyzed collected data. Qualitative data was done by inferential analyses using chi-square test for the independent groups. The significant level was detected at $p$ value $<0.050$; otherwise, it is not significant. The $p$ value is a statistical measure for the probability that observed results in the study chancily occurred.

\section{Results}

One hundred and sixty male patients presented with left-sided primary varicocele who met the inclusion criteria had been included for the study during the period between Feb 2010 and Jan 2015. Their mean age was $14.25 \pm 1.6$ years (ranged 13-16 years). No significant inter-group differences were seen in aspects of age or varicocele grade. All patients underwent lymphatic sparing laparoscopic varicocelectomy and they were stratified into two equal groups; group A $(n=80)$ underwent lymphatic sparing laparoscopic Palomo varicocelectomy while group B $(n=80)$ underwent lymphatic sparing laparoscopic varicocelectomy with testicular artery preservation.

Clinical presentation and demographic data were balanced and comparable in both groups (Table 1).

All cases were completed laparoscopically without conversion or intraoperative complications in any case.

In 8 cases of group $\mathrm{B}$, the testicular artery pulsations were seen only after the installation of diluted warm papaverine hydrochloride.

The mean operative time was $(35 \pm 2.8 \mathrm{~min})$ for group A while for group B it was $(40 \pm 2.6 \mathrm{~min})$ with a statistically significant difference $(p=0.001)$.

There was one case $(1.25 \%)$ of persistent varicocele in group A compared with 8 cases for group B with a significant difference $(p=0.016)$, confirmed by color Doppler U/S. The case of persistent varicocele in group

Table 1 Demographic data and clinical presentation in both

\begin{tabular}{lll} 
groups & Group A [n (\%)] & Group B [n (\%)] \\
\hline Groups & 80 & 80 \\
\hline Number of patients & $48(60)$ & $52(65)$ \\
Grade 3 & $32(40)$ & $28(35)$ \\
Grade2 & $44(55)$ & $40(50)$ \\
Asymmetry & $18(22.5)$ & $16(20)$ \\
Scrotal symptoms &
\end{tabular}

Age [(mean \pm SD) range] (years) $14.25 \pm 1.6(13-16)$
A decreased to grade one (non-refluxing) with no surgical intervention needed.

The $8(10 \%)$ cases of persistent varicocele, 4 cases decreased from grade 3 varicocele to grade 1 confirmed by color Doppler U/S without negative affection on the testicular size and hence followed up without redosurgery. The remaining 4 cases were of grade 2 and underwent redo-laparoscopic Palomo (without testicular artery preservation) and passed uneventfully. Varicocele disappeared in 79/80 cases (98.75\%) in group A and disappeared in $72 / 80$ cases $(90 \%)$ in group B (Table 2).

No postoperative hydrocele or testicular atrophy in both groups.

Postoperatively, testicular catch-up growth started early with the artery sparing group B during the third month and after 6 months in the artery ligation group A but without significant differences (Table 3). Catch-up had been achieved in 71/80 (88.75\%) cases and 68/80 (85\%) cases in group B and group A respectively. The remaining $9 / 80(11.25 \%)$ cases in group $B$ and $12 / 80$ (15\%) cases in group A showed no catch-up in testicular size. The testicular catch-up growth was noted in 139 $(86.8 \%)$ of 160 patients.

No cases of intraoperative venography or intraoperative Doppler U/S were done in this study. Semen analysis was not performed to any of the study patients.

\section{Discussion}

In the pediatric population, varicocele incidence varies with age, in boys aged 2-10 years, the incidence was lower than $4 \%$ while in boys aged 11-14 years old, it was $7.8 \%$. The prevalence is the same as those in adults in the age group from 15-19 years detected as about $14.1 \%$ [9].

Varicocele is the most common cause of secondary infertility in men causing a decrease in semen parameters and testicular function [10]. It was accompanied by a loss of testicular mass that is increased with age [11]. Varicocele is still without a gold standard treatment [12].

Shiu et al. believe that meticulous dissection and preservation of the testicular artery and the lymphatic vessels minimized the postoperative complications [13].

Table 2 Postoperative results

\begin{tabular}{lll}
\hline & Group A & Group B \\
\hline Number of patients & 80 & 80 \\
Persistence of varicocele & $1(1.25 \%)$ & $8(10 \%)$ \\
Redo-laparoscopic Palomo & --- & 4 \\
Cure & $79(98.75 \%)$ & $72(90 \%)$ \\
Postoperative testicular catch-up & $71(88.75 \%)$ & $68(85 \%)$ \\
\hline
\end{tabular}


Table 3 Evaluation of testicular catch-up of the left side (pre-operative and after 24 months post-operatively)

\begin{tabular}{llll}
\hline Variables & Preoperative testicular volume & Postoperative testicular volume & $p$ value \\
\hline Group A & $14.1 \pm 4.6$ & $17.1 \pm 5.1$ & 0.001 \\
Group B & $12.2 \pm 3.1$ & $16.3 \pm 4$ & 0.001 \\
\hline
\end{tabular}

Laparoscopic varicocelectomy was considered as a minimally invasive surgery with optical magnification. However, the preservation of the testicular artery had a higher recurrence rate [14].

Rizkala et al. found that the recurrence of varicocele after testicular artery preservation was $19 \%$ versus 1 $3 \%$ where the artery was not preserved without any reported testicular atrophy with testicular artery ligation [15].

Zampieri et al. established that testicular artery sparing had much postoperative semen parameters greater than mass ligation including that artery [16].

Feber et al. study had a 96\% success rate, which was attributed to testicular artery ligation [17].

Atassi et al. established that the open Palomo's technique with testicular artery ligation produced equal testicular growth in comparison to the artery sparing techniques [18].

For intra-operative detection of the testicular lymphatics, there are three different modes of injection: the sub-dartoic, the intra-parenchymal, and the intravaginal. The sub-dartoic injection is done between the dartos and parietal tunica vaginalis space. This is a feasible, rapid and safe method, while its preferred lymphatic pathway is the scrotal one which drains to the inguinal nodes and partially to the testicular system. The intraparenchymal injection is obtained by a fine needle just within the testis body. This is the most specific and faster approach due to the related regional lymphatic drainage. Intravaginal injection is done in the narrow space between the two layers of tunica vaginalis that is the least performed and the most difficult approach [11].

Testicular atrophy is a rare occurrence and paternity has not been a problem after adolescent varicocelectomy using mass ligation [19]. In a multicenteric Italian research conducted on 161 pediatric and adolescent patients, only $2.2 \%$ recurrence had been detected with the laparoscopic Palomo technique against 3.5\% with the modified laparoscopic Palomo with testicular artery preservation without any testicular atrophy in both groups [20].

Koyel et al. found that the testicular artery preservation has eliminated the risk of testicular atrophy postoperatively, particularly in patients who had previous inguinal surgery [21].

Mathias et al. found that there was nil significant difference between resection of the testicular artery or its preservation concerning recurrence of varicocele
(3.2\% vs. $5.5 \%)$ or postoperative incidence of hydrocele (9.7\% vs. $11.4 \%)$ in lymphatic sparing varicocelectomy [22].

Poddoubnyi et al. concluded that testicular artery ligation was preferred as no significant difference was observed in testicular blood flow between artery preservation and artery non-preservation with similar results on semen quality and postoperative paternity rate [23].

Esposito $\mathrm{C}$ et al. believed that the standard treatment for varicocele in pediatrics is the lymphatic sparing laparoscopic Palomo varicocelectomy using preoperative intra-dartoic isosulfan blue injection as it is technically easy and fast with no more than $1 \%$ recurrence rate [24].

In this study, lymphatic sparing laparoscopic varicocelectomy was feasible in all patients with no postoperative hydrocele in both groups. Testicular artery ligation in group A and testicular artery preservation in group B were done with a significant difference in varicocele persistence that was present in $1.25 \%, 10 \%$ in group A and group B respectively. These results are similar to that of Schwentner [14], Rizkala [15], Feber [17], and Esposito [24] in consideration to high varicocele persistence with artery preservation more than with artery ligation.

Artery preservation procedure in group B takes a longer time $(40 \pm 2.6 \mathrm{~min})$ with a significant difference ( $p=0.001)$ than that of group A $(35 \pm 2.8 \mathrm{~min})$.

In this study, testicular catch-up growth was detected in $139(86.8 \%)$ of 160 patients that were the same as those detected as before in the literature. Stephen et al. [25] explained the catch-up growth in 63\% of 136 patients after 1 year. Yaman et al. [26] had 65.5\% catchup growth of 92 patients at 1 year after lymphatic sparing microsurgical sub-inguinal varicocelectomy. In the same way, Koyle et al. [21] had $82 \%$ catch-up growth after 1 year of follow-up.

In this study, no testicular atrophy had been reported in both groups that were comparable to that was reported by other studies done by Atassi et al. [18] and Poddoubnyi et al. [23].

The strength of the present study is that the two groups of patients were well balanced as regard preoperative clinical presentation and demographic data. The same surgical team performed all procedures with the same surgical principles. Finally, all patients had objective long-term follow-up by U/S for the detection of complications and precise assessment of the testicular catch-up with every visit. 


\section{Limitations}

These observations represent the experience of a single center of pediatric surgery in 5 years, which may not be representative of the whole field and may reflect an individual achievement of surgical skill that may have affected the results; also, semen analysis was not included. Spontaneous testicular growth at pre-pubertal age is possible, may be considered as catch-up growth, because we cannot differentiate between spontaneous and postoperative catch-up. Also, a larger randomized study was required to evaluate and assist the importance of this technique and confront it with another technique.

\section{Conclusion}

Both lymphatic sparing laparoscopic varicocelectomy with or without testicular artery preservation procedures are effective methods for varicocele treatment in children and adolescents with good testicular catch-up rate, however, the recurrence rate of varicocele is higher with testicular artery preservation.

Lymphatic sparing laparoscopic Palomo varicocelectomy was superior to laparoscopic varicocelectomy with testicular artery preservation as regard varicocele persistence and operative time and hence is preferable for the management of primary pediatric varicocele.

Future researches with larger sample size and longer duration of follow-up till adulthood and after marriage are needed to detect the late benefits or risks of either surgical technique as regard the testicular integrity and function together with the future paternity and also, to resolve the debate between preservation and nonpreservation of the testicular artery during varicocelectomy and which technique of them is preferable.

\section{Abbreviations}

MB: Methylene blue; U/S: Ultrasound; CO2: Carbone dioxide; SPSS: Statistical Package for Social Sciences

\section{Acknowledgements}

"Not applicable"

\section{Availability of supporting data}

Available

\section{Authors' contributions}

Protocol/design development by: Yehya A, Abdalrazek M, and Fathy A.Data collection or management: Fathy A, Gamaan I, and El-Batal W. Data analysis: Abdalrazek M, Gamaan I, and Fathy A. Manuscript writing/editing: Yehya A and Abdalrazek M. The author(s) read and approved the final manuscript.

\section{Authors' information \\ Fulfilled at the first page}

\section{Funding}

Abdelaziz Yehya, Mohamed Abdalrazek, Ibrahim Gamaan, Ahmed Fathy, and Wael El Batal have no financial support or funding.

\section{Ethics approval and consent to participate}

With the approval of our institutional ethical committee and written informed consents were obtained from all patients.

\section{Consent for publication}

Approved

\section{Competing interests}

Abdelaziz Yehya, Mohamed Abdalrazek, Ibrahim Gamaan, Ahmed Fathy, and Wael El Batal have no competing interests.

\section{Author details}

${ }^{1}$ Department of Pediatric Surgery, Faculty of Medicine Al-Azhar University, Nasr City, Cairo, Egypt. ²Department of Pediatric Surgery, Al-Azhar University Hospitals, Darrasa, Cairo, Egypt. ${ }^{3}$ National Research Center, Cairo, Egypt.

Received: 16 January 2020 Accepted: 15 May 2020

Published online: 02 July 2020

\section{References}

1. Kolon TF. Evaluation and management of the adolescent varicocele. J Urol. 2015;194:119e201.

2. Kurtz MP, Zurakowski D, Rosoklija I, et al. Semen parameters in adolescents with varicocele: association with testis volume differential and total testis volume. J Urol. 2015;193:1843-7.

3. Fine RG, Gitlin J, Reda EF, Palmer LS. Barriers to use of semen analysis in the adolescent with a varicocele: survey of patient, parental, and practitioner attitudes. J Pediatr Urol 2016; 12: 41.e1-e41.e6.

4. Akbay E, Cayan S, Drouk E, Duce MN, Bozlu M. The prevalence of varicocele and varicocele related testicular atrophy in Turkish children and adolescents. BJU Int. 2000;4:490-3.

5. Tu D, Glassberg Kl. Laparoscopic varicocelectomy. BJU Int. 2010;7:1094-104.

6. Kocvara R, Dvoracek J, Sedlacek J, Dite Z, Novak K, et al. Lymphatic sparing laparoscopic varicocelectomy: a microsurgical repair. J Urol. 2005, May; 173(5):1751-4

7. Dubin LL, Amelar RD. Varicocelectomy as therapy in male infertility. A study of 504 cases. J Urol. 1975;113:640

8. Cimador M, DI pace M, Castagnetti M, et al. Comprehensive laparoscopic approach to pediatric varicocele based on preoperative color Doppler U/S assessment. Surg Endosc 2008; 22; 701-705.

9. Feber KM, Kass EJ. Surgery for the adolescent varicocele. Dialogues. Pediatric Urol. 2008:30:10-1

10. Cheval MJ. Purcell MH; Varicocelectomy: incidence of external spermatic vein involvement in the clinical varicocele. Urology. 1992;39:573-8.

11. Alessio AD, Piro E, Beretta F, Brugnoni M, Marinoni F, Abati L; Lymphatic preservation using methylene blue dye during varicocele surgery a single center retrospective study J of pediatric urology 2008:4;138-140.

12. Parrott TS, Hewatt L. Ligation of testicular artery and vein in adolescent varicocele; 1994; 152(2), 791-793.

13. Shiu. DC, Chia CW Victor, Chen HH, Stephen S D, Yang YCT. Minilaparoscopic varicocelectomy with preservation of testicular artery and lymphatic vessels by using intracorporeal knot tying technique: five years of experience ; World J Surg 2011;35,1785-1790.

14. Schwentner C, Radmayer C, Lunacek A, et al. Laparoscopic varicocele ligation in children and adolescents using isosulphan blue: a prospective randomized trial. B J U Int 2006:98:861-5.

15. Rizkala E, Fishman A, Gitlin J, et al. Long term outcomes of lymphatic sparing laparoscopic varicocelectomy. J pediatric Uro. 2013:9:458-63.

16. Zampieri N, Zuin V, Corroppolo M, et al; Varicocele and adolescents semen quality after 2 different laparoscopic procedures J Androl 2007;28;727-733.

17. Feber K.M., Kass E.J., , Varicocelectomy in adolescent boys: long-term experience with the Palomo procedure, J Urol 2008 ,180(4 Suppl.), 1657-1659.

18. Atassi O, Kass EJ, Steinert BW. Testicular growth after successful varicocele correction in adolescent; comparison of artery sparing techniques with Palomo's procedure. J Urol. 1995:153-482.20.

19. Glassberg Kl, Poon SA, Gjertson CK, et al. Laparoscopic lymphatic sparing varicocelectomy in adolescent. J Urol. 2008;180:326-30.

20. Esposito C, Monguzzi, GL, Gonzalez Sabin , M A, Rubino R, Montinaro L, papparello A, et al ;Laparoscopic treatment of pediatric varicocele ;a 
multicentre study of Italian society of vedio surgery in infancy .J Urol 2000 ;163; 1944-1946.

21. Koyle MA, Oottamasathien S, Baraqwi A, Rajimwale A, Furness PD.

Laparoscopic Palomo's varicocele ligation in children and adolescent; results of 103 cases. J Urol. 2004;172:1749-52.

22. Mathias M, Manfred J, Sabine B, Christian H, Kay PB, Michael L, Jan R, Bernd H. Laparoscopic surgery versus ante-grade scrotal sclerotherapy: retrospective comparison of two different approaches for varicocele treatment. European Urol. 2006:49:384-7.

23. Poddoubnyi IV, Dronov AF, Kovarskii SL, et al. Laparoscopic ligation of testicular veins for varicocele in children. A report of 180 cases. Surg Endosc. 2000;14:1107-9.

24. Esposito C, Escolino M, Castagnetti M, Cerulo M, Settimi A, Cortese G, Turrà F, lannazzone M, Izzo S, Servillo G. Two decades of experience with laparoscopic varicocele repair in children: standardizing the technique. JPU. 2017;14, 10.e1e10.e7.

25. Stephen A,Poon,Kristin A.Kozakowski,G.Joel Decastro,Carl K,Gjertson,Kenneth I.Glassberg. Adolescent varicocelectomy: postoperative catch-up growth is not secondary to lymphatic ligation. JPU. 2009; 5;37-41.

26. Yaman O, Soygur T, Zumrutbas AE, Resorlu B. Results of microsurgical subinguinal varicocelectomy in children and adolescents. Urology. 2006;68: $410-2$.

\section{Publisher's Note}

Springer Nature remains neutral with regard to jurisdictional claims in published maps and institutional affiliations.

\section{Submit your manuscript to a SpringerOpen ${ }^{\circ}$ journal and benefit from:}

- Convenient online submission

- Rigorous peer review

- Open access: articles freely available online

- High visibility within the field

- Retaining the copyright to your article

Submit your next manuscript at $\boldsymbol{\nabla}$ springeropen.com 